\title{
Responsabilidade social no ensino em administração: um estudo exploratório sobre a visão dos estudantes de graduação*
}

\author{
Renata Céli Moreira da Silva** \\ Marie Agnes Chauvel***
}

SumÁrio: 1. Introdução; 2. Revisão da literatura; 3. Metodologia; 4. Descrição e análise dos resultados; 5 . Considerações finais e sugestões para futuras pesquisas.

Summary: 1. Introduction; 2. Literature review; 3. Methodology; 4. Description and analysis of the results; 5 . Final considerations and suggestions for further research.

Palavras-chave: responsabilidade social; ensino; administração.

KEY WORDS: social responsibility; education; administration.

O propósito deste trabalho foi estudar a visão dos estudantes de administração sobre o ensino da responsabilidade social corporativa (RSC) nos cursos de graduação. Foi feita uma revisão de literatura que abordou o conceito de RSC e suas dimensões, bem como sua inserção no ensino superior de administração. Em seguida, foram realizadas 30 entrevistas em profundidade com alunos de administração do Rio de Janeiro próximos ao período de formatura. Os resultados mostraram que os entrevistados se preocupam com o tema e consideram a RSC importante. Muitos avaliaram que o espaço dado ao tema na graduação é insuficiente e que o assunto é abordado

\footnotetext{
* Artigo recebido em ago. 2009 e aceito em out. 2010.

** Mestre em administração de empresas pela Pontifícia Universidade Católica do Rio de Janeiro (IAG/Puc-Rio). Graduação em administração pelo Ibmec-Rio. Doutoranda em administração de empresas do IAG/PUC-Rio. Endereço: av. Rui Barbosa 457, ap. 301 - São Francisco - CEP 24360-440, Niterói, RJ, Brasil. E-mail: renata.celi@gmail.com.

*** Doutora em administração pela Coppead, da Universidade Federal do Rio de Janeiro (UFRJ), mestre em psicologia social e do trabalho pela Universidade de São Paulo (USP) e psicóloga pela USP. Professora adjunta do Departamento de Ciências Administrativas e Contábeis (Decac) da Universidade Federal de São João del-Rei (UFSJ). Endereço: Alameda das Palmeiras, 70, Portal Vila Rica — Colônia do Marçal — CEP 36302-722, São João del-Rei, MG, Brasil. E-mail: mariechauvel@gmail.com.
} 
de forma superficial. Vários declararam ter aprendido mais sobre RSC em meios externos, como revistas, jornais, trabalho. Confrontando-se os conhecimentos dos entrevistados com a literatura, observou-se uma visão limitada da RSC. Verificouse que os entrevistados têm dúvidas e questionamentos sobre RSC, essencialmente relativas ao próprio conceito e à sua aplicação na prática da administração. De modo geral, os resultados sugerem que os entrevistados estão sensibilizados para o tema. Mais que teoria, porém, eles desejam saber como a RSC pode ser posta em prática dentro das organizações. O final do trabalho traz recomendações às instituições de ensino e sugestões para futuras pesquisas.

Social responsibility in administration's education: an exploratory study about the vision of the undergraduate students

The purpose of this study was to explore the student's vision of Corporate Social Responsibility (CSR) and their view about the teaching of CSR in undergraduate courses. Thirty Administration students of Rio de Janeiro were interviewed. The results showed that the respondents are concerned about this issue, since they consider that it is important for the practice of Administration. Some respondents said that the space given to CSR in the university is inadequate and, thus, it should be greater. They also said that the approach could be improved, since sometimes it is considered a superficial approach, although the content is correct. Many respondents learned more about it out of university, such as in magazines, newspapers, or at work. Many respondents had a more restricted view about the definition of CSR. The majority addressed only a few dimensions of it, showing little knowledge about it. Some respondents have doubts about CSR, especially basic questions, concerning the concept of the theme. Others have also showed doubts regarding the practice of CSR. Overall, the results suggest that respondents are sensitized to this issue. More than theory, however, they want to know how the CSR can be put into practice. The end of this research brings some recommendations to educational institutions and suggestions for future research.

\section{Introdução}

Recentemente, o tema responsabilidade social corporativa (RSC) tem sido alvo de inúmeros debates. O tema tem sido muito abordado não só no meio acadêmico, como também no ambiente empresarial.

A RSC surgiu para resolver determinados problemas de desenvolvimento da sociedade e do ambiente (Schommer e Rocha, 2007). Collier e Wanderley (2004) apontam que as empresas são agentes globais de mudança e suas ações não são somente econômicas; por isso é necessário que as empresas assumam as responsabilidades pelos impactos de suas ações para se comprometerem com um futuro sustentável e próspero para a economia global. 
Logo, pode-se dizer que mundialmente há uma pressão da sociedade para que as organizações tenham práticas socialmente responsáveis, e essa pressão está cada vez maior (Klein, 2004; Mohr e Webb, 2005; Aguilera et al., 2007; Hond e Bakker, 2007; Marquis et al., 2007; Rodríguez e Lemaster, 2007). Segundo Gerde (2001), as empresas que não respondem a essa demanda perdem legitimidade.

Isso se torna particularmente visível quando se considera a crescente preocupação com os recursos do planeta, com os problemas sociais (Dufloth e Bellumat, 2005) e a repercussão de escândalos relacionados à irresponsabilidade de empresas (Carson, 2003; Neubaum e Zahra, 2006). Um exemplo notório é o da Nike, que tinha práticas de trabalho inadequadas, cuja divulgação abalou a imagem da empresa (Auger et al., 2003; Detienne e Lewis, 2005). O Brasil e o mundo apresentam problemas éticos que chamam a atenção para sua resolução (Urdan e Huertas, 2004).

Faria e Sauerbronn (2008) apontam entre os motivos das discussões sobre RSC a globalização acelerada, o crescente poder político e econômico das grandes empresas e os grandes escândalos corporativos. Com isso, Wood (1991b) afirma que as empresas precisam responder à seguinte pergunta: Como eu posso contribuir para construir uma boa sociedade?

Por conseguinte, o tema da responsabilidade social vem se tornando cada vez mais presente na academia e na vida empresarial. Diante desse quadro, torna-se relevante saber se e como esse tema está sendo difundido e discutido em salas de aula da graduação em administração. Sobretudo, é importante atentar para o que os alunos de graduação retiram desse ensino. É preciso saber se as instituições de ensino estão sendo capazes de formar profissionais aptos para a gestão da responsabilidade social, que conheçam os significados desse conceito, os debates que o cercam e suas implicações; que possam se tornar gestores éticos e socialmente responsáveis (Medeiros et al., 2007).

Portanto, o objetivo deste trabalho é levantar, descrever e analisar a visão que os formandos em administração possuem sobre a responsabilidade social e sobre seu ensino no curso de graduação.

\section{Revisão da literatura}

\subsection{Responsabilidade social corporativa (RSC)}

Existem inúmeras definições sobre o que é RSC, o que mostra que o conceito ainda está em construção (Ashley, 2002; Higuchi e Vieira, 2007). Para Matten e Moon (2008), essas definições podem inclusive variar de país para país. 
Pereira e Campos Filho (2006) verificaram numa pesquisa bibliográfica que há quatro modelos de RSC que possuem grande representatividade nas publicações acadêmicas. Os principais modelos selecionados foram de Carroll (1991), Wood (1991a), Enderle e Tavis (1998) e Quazi e O’Brien (2000).

Para Carroll (1991), a RSC é composta por quatro componentes: econômico, legal, ético e filantrópico. O componente econômico diz respeito a responsabilidades como: ter um desempenho consistente maximizando os ganhos, estar comprometido com a lucratividade, ter lucros consistentes. O componente legal diz respeito a responsabilidades como: ter um desempenho levando em consideração as leis, cumprir regulamentos federais, estaduais e locais. O componente ético diz respeito a responsabilidades como: ter um desempenho consistente com as expectativas morais e éticas da sociedade, reconhecer e respeitar novas ou atuais normas éticas e morais adotadas pela sociedade, fazer o que é esperado moral e eticamente. E o componente filantrópico diz respeito a contribuir com recursos para a comunidade para melhorar seu bem-estar.

Já o modelo de Wood (1991a) aborda a RSC da ótica do desempenho social e possui três dimensões, como pode ser visto no quadro a seguir.

\section{Quadro}

\section{Modelo de Wood}

\begin{tabular}{|l|}
\hline \multicolumn{1}{|c|}{ Modelo de Wood (1991) } \\
\hline Dimensão 1: Princípios de RSC \\
\hline Legitimidade: Princípio institucional \\
Responsabilidade pública: Princípio organizacional \\
Arbítrio dos executivos: Princípio individual \\
\hline Dimensão 2: Processos de responsabilidade social corporativa \\
\hline Avaliação do ambiente \\
Gerenciamento dos stakeholders \\
Gerenciamento das questões \\
\hline Dimensão 3: Resultados das ações de responsabilidade social \\
\hline Impactos sociais (interno e externo) \\
Programas sociais \\
Políticas sociais \\
\hline
\end{tabular}

Fonte: Wood (1991a).

O modelo de Enderle e Tavis (1998) considera que a RSC possui as dimensões econômica, social e ambiental. A dimensão econômica diz respei- 
to a responsabilidades como maximizar lucros e ter produtividade. A dimensão social se refere a responsabilidades como cumprimento de leis, respeito ao patrimônio cultural, engajar-se em ações sociais filantrópicas e iniciativas educacionais. A dimensão ambiental diz respeito ao comprometimento com o desenvolvimento sustentável. Os autores também sublinham a relação das organizações com os stakeholders, já que a RSC está associada não só aos acionistas, mas a um grupo maior. De acordo com Souza e colaboradores (2003), os stakeholders são: acionistas, fornecedores, consumidores, sociedade, comunidade local, governo, empregados e dependentes, concorrentes e meio ambiente.

Além das três dimensões do modelo de Enderle e Tavis (1998), os autores também propõem que as empresas podem estar em diferentes estágios, chamados de três níveis éticos. O nível 1 é quando a empresa cumpre os mínimos requisitos éticos, sendo o maior objetivo o de maximização do lucro. $\mathrm{O}$ nível 2 é quando a organização possui compromissos além do objetivo econômico, como a empresa provedora do bem-estar social. O nível 3 é quando a empresa aspira a ideais éticos, sendo proativa em face das demandas sociais.

Já Quazi e O’Brien (2000) propõem um modelo de RSC que pode ser visto na figura a seguir.

Figura

Modelo de Quazi e O'Brien (2000)

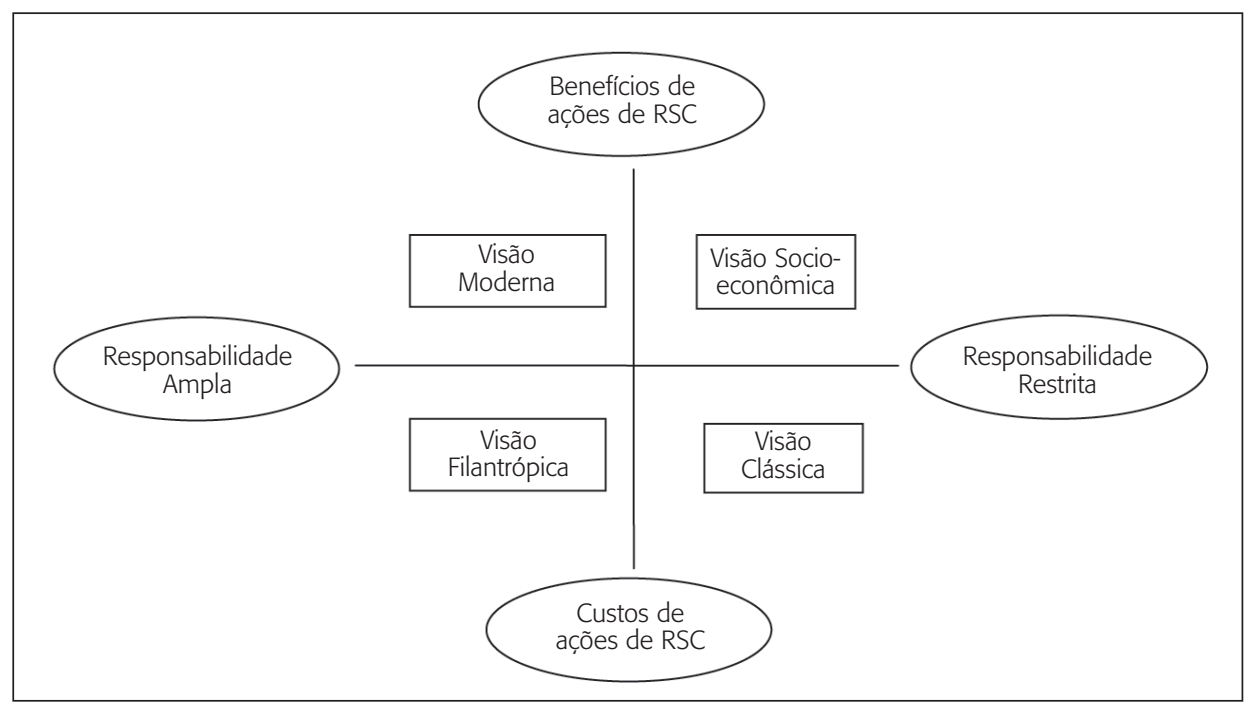

Fonte: Quazi e O'Brien (2000). 
Para Quazi e O'Brien (2000), as ações de RSC podem ser amplas ou restritas. São amplas quando envolvem atividades que vão além da visão clássica e econômica. São restritas quando se limitam a uma visão de maximização de lucros. O modelo possui quatro quadrantes: visão clássica, visão socioeconômica, visão filantrópica e visão moderna.

A visão clássica diz respeito à maximização dos lucros para os acionistas. Ela enxerga ações sociais como custos para a organização. A visão socioeconômica aceita algumas práticas de RSC desde que tragam benefícios para a organização, como construir um bom relacionamento com clientes e fornecedores. A visão filantrópica diz respeito à participação em ações de caridade como resultado de sentimentos éticos em relação à sociedade. A visão moderna afirma que ações de RSC geram benefícios para a empresa no curto prazo e no longo prazo e também considera que a empresa precisa estar atenta aos stakeholders (Quazi e O’Brien, 2000).

Além dessas definições há outras muito citadas na literatura nacional. Uma delas é de Ashley (2002:6), que define a RSC como

compromisso que uma organização deve ter para com a sociedade, expresso por meio de atos e atitudes que a afetem positivamente, de modo amplo, ou a alguma comunidade, de modo específico, agindo proativamente e coerentemente no que tange a seu papel específico na sociedade e a sua prestação de contas para com ela. A organização, nesse sentido, assume obrigações de caráter moral, além das estabelecidas em lei, mesmo que não diretamente vinculadas a suas atividades, mas que possam contribuir para o desenvolvimento sustentável dos povos. Assim, numa visão expandida, responsabilidade social é toda e qualquer ação que possa contribuir para a melhoria da qualidade de vida da sociedade.

Ashley (2002:6) ainda cita os autores Melo Neto e Froes (1999) ao dizer que a RSC engloba o público interno e externo e aponta que a RSC possui sete vetores: "apoio ao desenvolvimento da comunidade na qual atua"; "preservação do meio ambiente"; "investimento no bem-estar de funcionários e dependentes e em um ambiente de trabalho agradável"; "comunicações transparentes"; "retorno aos acionistas"; "sinergia com os parceiros"; "satisfação de clientes e consumidores". Esses vetores estão relacionados aos stakeholders da organização.

Para Ashley (2002), a RSC é vista hoje como algo incorporado à estratégia da empresa e é fundamental para incrementar os lucros e o desenvolvimento da empresa. Portanto, a RSC alia a estratégia a ações sociais para garantir o lucro e também a satisfação dos clientes e da sociedade. 
Além dessas definições, há várias discussões em torno do tema. Uma das questões frequentemente debatidas é a da incorporação da RSC às estratégias empresariais. Bowen (2007) afirma que as empresas passaram a adotar a RSC como parte de sua estratégia, alocando recursos estrategicamente para atingir objetivos sociais de longo prazo e vantagem competitiva. Sen e Bhattacharya (2001) e Bonatto e colaboradores (2007) sublinham que a RSC é boa para a imagem da empresa. Faria e Sauerbronn (2005:1) defendem que a área de estratégia empresarial se apropriou do tema RSC em razão do interesse das grandes corporações em "camuflar certas assimetrias sociais que vêm sendo causadas ou ampliadas pelas estratégias corporativas". Santos (2008:15) aponta que o propósito de legitimação é um dos motivos para a prática da RSC. Segundo o autor, trata-se de "um meio de a organização institucionalizar a sua imagem e as suas operações, consolidando assim uma posição competitiva mais forte no longo prazo". No mesmo artigo, o autor sublinha também que não se deve falar em substituição ao papel do Estado. A RSC, segundo ele, "não pode nunca estar associada a uma intervenção menor do poder público, principalmente naqueles temas que não são de interesse das empresas". Assim, o correto seria falar em parceria (e não substituição). Não há aqui espaço para aprofundar a descrição dessas discussões, que dizem respeito ao papel social das empresas e à tensão eventualmente existente entre os objetivos empresariais e os interesses da sociedade, mas é importante registrá-las, pois, como se verá adiante, este é um ponto que suscita também dúvidas entre os estudantes pesquisados neste trabalho.

\subsection{Ensino em administração e a RSC}

Não são somente as empresas que estão adotando práticas de RSC, há universidades que também estão adotando essa postura (Atakan e Eker, 2007) e há discussões sobre o papel das instituições de ensino na difusão da RSC e das práticas a ela associadas. Isso ocorre porque foram notados comportamentos antiéticos nos negócios e por trás dessas ações irresponsáveis estão gestores que pertenceram a universidades de administração (Urdan e Huertas, 2004; Medeiros et al., 2007).

Urdan e Huertas (2004) sublinham que a educação é uma solução para evitar essas ações antiéticas, já que a educação possui um papel fundamental na formação dos indivíduos. Nesse mesmo contexto, Gonçalves-Dias e colaboradores (2006) falam do valor da educação e acrescentam que é importante que os educadores capacitem os alunos de administração não só a atingir um 
bom desempenho empresarial, mas também a minimizar os problemas socioambientais. Canopf e Passador (2004) afirmam que a universidade de administração deve assumir o papel fundamental de proporcionar ao aluno uma formação que contemple aspectos de RSC, já que esses alunos irão ocupar cargos em empresas e irão enfrentar situações que envolvam, por exemplo, aspectos éticos ou aspectos de conciliação de interesses organizacionais e sociais. Xavier e colaboradores (2006) também alertam para a necessidade de um maior esforço para formar profissionais conscientes em relação à ética. Muijen (2004) escreve que a RSC começa na universidade e defende a ideia de que a universidade deve ensinar RSC aos alunos de graduação.

Com isso, é importante saber se e como a RSC está sendo abordada no ensino de graduação em administração. No Brasil, ainda há poucos estudos sobre esse tema, como exemplo o estudo de Fourneau e Serpa (2006), que investigou o ensino da ética - que é uma dimensão da RSC, conforme Carroll (1991) — segundo a percepção dos alunos e seu resultado mostrou que deveria haver mais espaço para esse tema.

Souza e colaboradores (2003) observam que, segundo as diretrizes curriculares nacionais para o curso de administração, entre as competências e habilidades requeridas no curso, há a necessidade de se passar a consciência da qualidade e das implicações éticas do exercício profissional, o que mostra uma abertura para o ensino da RSC. E, em relação aos conteúdos curriculares, apresenta-se uma preocupação com o ambiente e as relações entre organizações e realidade social. Canopf e Passador (2004) também relatam que, de acordo com as diretrizes curriculares nacionais, a preocupação com as questões sociais precisa estar presente no meio acadêmico e a universidade deve buscar formar profissionais capazes de corresponder às expectativas da sociedade.

\section{Metodologia}

Em razão da escassez de pesquisas sobre o tema, o presente estudo caracteriza-se como um estudo exploratório. Geralmente, o estudo é exploratório quando há pouco conhecimento sobre o tema a ser abordado (Aaker et al., 2004), como ocorre nesta pesquisa.

O estudo também se caracteriza como uma pesquisa descritiva, visto que possui o propósito de descrever um fenômeno (Gil, 1987): a visão dos estudantes de administração sobre RSC e seu ensino. A metodologia utilizada foi qualitativa. De acordo com Gephart (2004), a pesquisa qualitativa fornece 
uma narrativa da visão da realidade dos indivíduos, sendo, portanto, descritiva. Ela ainda dá uma ênfase aos detalhes situacionais, permitindo uma boa descrição dos processos (Gephart, 2004). Ela é importante para a administração, pois fornece insights que são difíceis de serem obtidos em uma pesquisa quantitativa (Gephart, 2004; Shah e Corley, 2006) e fornece um entendimento mais profundo sobre o que está sendo explorado (Hanson e Grimmer, 2007).

Numa primeira etapa, foram escolhidas cinco instituições de ensino, localizadas na região do Grande Rio de Janeiro, que ofereciam cursos de graduação em administração. Foram selecionadas instituições que possuem uma boa avaliação do ensino superior (conceito cinco no Enade de 2006). Em seguida, foi efetuado um levantamento nos sites dos programas de graduação selecionados a fim de verificar a oferta de disciplinas relacionadas ao tema RSC.

Numa segunda etapa, procedeu-se a uma pesquisa de campo junto aos estudantes de graduação em administração dos cursos selecionados. A coleta de dados foi feita através de entrevistas em profundidade guiadas por um roteiro previamente estabelecido com base na revisão de literatura. Os tópicos abordados foram os seguintes: cursos que os informantes tinham tido sobre o tema RSC; sua satisfação/insatisfação com o espaço e a abordagem dados ao assunto; visão dos formandos sobre RSC; questionamentos e dúvidas sobre o assunto; aplicações da RSC na prática profissional; avaliação do tratamento dado ao tema na faculdade em que estudavam ou tinham estudado. As entrevistas foram feitas nas faculdades onde os informantes estudavam e integralmente gravadas para posterior transcrição.

A seleção dos entrevistados foi efetuada da seguinte forma: como a pesquisa visava levantar a percepção dos alunos, foram escolhidos seis alunos do curso de graduação em administração (que se formaram no $1^{\circ}$ ou $2^{\circ}$ semestres de 2008 ou iam se formar no $1^{\text {o }}$ semestre de 2009) de cinco faculdades das cidades do Rio de Janeiro e Niterói, pertencentes ao estado do Rio de Janeiro. Assim, no total, foram entrevistados 30 alunos. Com essa quantidade de entrevistas foi possível observar o fenômeno de saturação (os conteúdos se tornam repetitivos, apontando que novas entrevistas já não trazem informações adicionais sobre o tema pesquisado). Importante ressaltar que as faculdades e os alunos não foram identificados na pesquisa, sendo atribuídos a eles códigos como entrevistado A1, A2, B1 etc.

Em razão do caráter qualitativo da pesquisa, os resultados não podem ser generalizados à população estudada (Kates, 1998). O que se espera é que eles possam contribuir para futuros estudos, auxiliando na construção de uma pesquisa quantitativa junto ao mesmo público e na elaboração de novos estudos junto aos demais atores envolvidos (universidades, coordenadores de 
cursos, professores; empresas, executivos envolvidos no recrutamento e na seleção de recém-formados, profissionais atuantes na área de RSC; responsáveis pela elaboração de diretrizes na área de ensino em administração).

\section{Descrição e análise dos resultados}

Este item foi dividido em três partes. A primeira mostra as disciplinas de RSC das faculdades, a segunda mostra o perfil dos entrevistados e a terceira descreve os resultados da pesquisa de campo realizada junto aos alunos.

\subsection{Disciplina de RSC nas faculdades}

De acordo com os sites das instituições pesquisadas, as faculdades A e B não possuem uma disciplina de RSC. A faculdade B possui uma disciplina obrigatória voltada para a ética em administração, que, segundo Carroll (1991), é uma das dimensões da RSC. A faculdade C também possui uma disciplina obrigatória voltada para a ética, chamada liderança e ética. E, segundo seu site, há uma disciplina eletiva chamada cidadania e liderança de organizações socialmente ativas.

A faculdade D possui uma disciplina obrigatória chamada políticas e gestão do meio ambiente; possui outra disciplina obrigatória voltada para a ética, chamada filosofia, métodos e ética. E, segundo seu site, também possui uma disciplina eletiva de gestão ambiental e desenvolvimento sustentável. Apesar de não constar em seu site a existência de uma disciplina voltada especificamente para RSC, alguns respondentes disseram que há uma eletiva sobre o tema.

A faculdade E possui uma disciplina voltada para a ética profissional e uma disciplina voltada para a responsabilidade social, que, segundo os respondentes da pesquisa, é uma disciplina eletiva.

\subsection{Perfil dos entrevistados}

O total de entrevistados foi 30. Desse total, 14 eram do sexo feminino e 16 do sexo masculino. A idade dos entrevistados está compreendida num intervalo de 21 a 29 anos, com exceção de dois entrevistados (um com 31 anos e o outro com 40 anos). Em relação à data de formatura, três entrevistados se formaram 
no $1^{\circ}$ semestre de 2008, 14 entrevistados se formaram no $2^{\circ}$ semestre de 2008 e 16 iam se formar no $1^{\circ}$ semestre de 2009.

Do total de entrevistados, 14 fizeram um trabalho sobre RSC na graduação em administração, 4 entrevistados cursaram uma disciplina específica de RSC e 2 entrevistados realizaram/estão realizando uma monografia sobre o tema. Além disso, 10 entrevistados tinham tido contato com atividades relacionadas à RSC em suas atividades profissionais (estágio ou emprego).

\subsection{Análise das entrevistas}

\subsubsection{Nível de interesse/preocupação com o tema}

Os entrevistados demonstraram preocupação com o tema. Disseram considerar a RSC algo importante para a prática da administração: "Para a prática das empresas, extremamente importante [...] É uma forma de agregar valor para a empresa no longo prazo" (Relato do Entrevistado D4).

Apontaram que a RSC é boa para a imagem da empresa (Sen e Bhattacharya, 2001; Bonatto et al., 2007), para o desenvolvimento da sociedade e do ambiente (Enderle e Tavis, 1998; Melo Neto e Froes, 1999; Ashley, 2002; Schommer e Rocha, 2007), para o desenvolvimento da empresa (Bowen, 2007) e para reduzir os impactos causados pelas organizações (Collier e Wanderley, 2004), como pode ser visto nos relatos a seguir.

Acho que é muito importante, como eu falei, porque a partir do momento que você está administrando uma empresa, você tem que entender que a sua empresa tem um impacto social e que você tem que analisar esses impactos para tentar mitigar e fazer com que o impacto da sua empresa seja o menor possível na sociedade (Relato da Entrevistada A1).

Eu acho que sim, é bastante importante [...] as empresas que praticam isso estão cada vez mais sendo mais bem vistas pela sociedade mesmo (Relato do Entrevistado B6).

Eu acho que é bastante importante porque [...] O Brasil, a maior parte do Brasil é, tipo, pobre, são pessoas que não têm condição nenhuma, e as pessoas não estão nem aí para isso. Também tem outra parte, tipo assim, a parte tipo ambiental, que eu acho que seria importante também [...] (Relato da Entrevistada E6).

Por outro lado, apesar dessas afirmações, a maioria dos pesquisados que tinha cursado a disciplina eletiva de RSC (quatro) disse que sua escolha 
tinha sido feita porque, primeiramente, a disciplina se encaixava no horário. Somente um respondente disse que cursou a matéria por achar o tema interessante. Houve entrevistados que disseram que cursariam essa matéria se existisse na sua faculdade, porém outro entrevistado disse que cursaria a disciplina de RSC se ela fosse obrigatória, mas, caso fosse eletiva, teria que ver se ela se adaptaria a seu horário.

Isso sugere que, se a instituição deseja reforçar o tema RSC na formação de seus alunos, talvez deva colocá-lo em disciplinas obrigatórias, já que as eletivas parecem ser escolhidas em função do horário. Também aponta que, em pesquisas - particularmente quantitativas baseadas em questionário - é preciso interpretar com cuidado respostas sobre a importância dada ao tema pelos alunos, já que, apesar de declarar que consideram o tema importante, os entrevistados (exceto um) não chegaram a priorizá-lo em sua formação.

\subsubsection{As aulas que tiveram sobre RSC ao longo da faculdade e a satisfação/insatisfação com o espaço e as abordagens dadas}

Em primeiro lugar, pôde ser observado existir uma falha na comunicação sobre as disciplinas oferecidas pela faculdade, já que foi visto que alunos de uma mesma faculdade tiveram respostas diferentes em relação à existência da disciplina de RSC. Enquanto uns responderam que não havia a disciplina de RSC, outros da mesma faculdade afirmaram que havia.

Somente quatro entrevistados disseram ter cursado uma disciplina de RSC. Os demais apontaram que, apesar de não haver disciplina sobre o tema, ele é abordado em algumas outras disciplinas, como marketing e recursos humanos. Porém, vários informantes julgaram que essa abordagem, embora correta e adequada em seu conteúdo, era superficial.

Algumas vezes, alguns professores falam sim, mas não é normal, não (Relato da Entrevistada B1).

É, aborda de maneira mais genérica, nada muito aprofundado (Relato do Entrevistado B6).

Não, não aborda muito não. Já teve algumas aulas de professores comentarem a respeito, mas nada, assim, muito específico não (Relato do Entrevistado C6). Olha, não me lembro. Sinceramente, de forma clara, não. Talvez comentando, mas não fazendo parte da disciplina mesmo, da grade, da matéria (Relato da Entrevistada D6). 
Olha, eu acho que não muito. Eu vi alguma coisa assim em Marketing, alguma coisa bem superficial, mas nada muito a fundo, assim [...] é muito básico mesmo, fala só sobre RSC é importante. Agora, não chega muito a fundo em ferramentas e algo mais (Relato do Entrevistado E4).

$\mathrm{O}$ pouco que falou, acho que sim (abordagem era adequada). Acho que foi bem dito, foi legal. Mas o problema é a quantidade, foi muito pouco [...] (Relato da Entrevistada E6).

Pode-se deduzir desses depoimentos que, ao menos na visão dos entrevistados, nos casos em que a RSC é abordada em outras disciplinas, não é tratada como tópico da ementa, a ser devidamente aprofundado, e sim como um ponto que é, às vezes, discutido em sala de aula. Alguns entrevistados até disseram que o tema é abordado de forma desestruturada, ou mesmo em resposta a demandas dos próprios alunos.

Não, às vezes, isso é citado, mas mais por interesse de algum aluno e tudo, mas os professores de maneira espontânea, poucas vezes ele fala sobre a importância da RSC. Às vezes o assunto surge e ele desenvolve um pouco, mas por livre e espontânea vontade, acho que isso não está no quadro, não (Relato do Entrevistado E3).

A maioria dos entrevistados considera que o espaço dado atualmente para o tema RSC é insuficiente.

Acho que poderia haver mais espaço, acho que poderia haver um espaço formal, porque às vezes é uma contribuição do professor. Às vezes não é uma coisa oficial, que está na ementa. Acho que poderia ter uma coisa mais formal, assim (Relato do Entrevistado A2).

Poderia haver espaço, acho que seria a palavra certa. Não há espaço, não há matérias. Eu acho que o currículo é realmente muito, muito sequinho, muito antigo. Não mudaram muita coisa, muita coisa está mudando e a universidade não está conseguindo captar essa mudança (Relato da Entrevistada B3).

Acho que poderia ter uma matéria específica, poderia dar mais espaço. Tem muita coisa para ser falada que não dá tempo de abordar sendo parte das matérias [...] Hoje em dia, tem tanto foco nisso, tem tantas matérias, jornal, revista, TV. As pessoas poderiam ter mais tempo para discutir. Você só conhece no geral, ninguém entra fundo (Relato da Entrevistada C5).

Poderia haver mais espaço e sendo uma matéria obrigatória, para poder, é, eu acho que todo administrador teria que ter essa ideia de RSC (Relato da Entrevistada D5). 
Chama atenção o aparente descompasso entre a exposição ao tema fora da sala de aula e o espaço dedicado a ele na faculdade. Vários entrevistados inclusive disseram que o que tinham aprendido sobre RSC vinha mais de meios externos à faculdade, como revistas, jornais, trabalho do que de disciplinas cursadas na graduação. É interessante notar também que interpretam isso como um sinal de desatualização da universidade, como se esta permanecesse alheia ao que se passa no mundo externo e nas empresas.

Bom, eu acho que dentro da faculdade, o que eu aprendi sobre RSC foi muito pouco. O que eu aprendi mais sobre RS vem do meu trabalho. E eu acho que é importante justamente porque a partir do momento que você vai administrar uma empresa, você tem que entender qual é a sua responsabilidade nesse assunto, para você não ficar sozinho, e saber que o mercado te cobra isso também, que as pessoas te cobram que você tenha RSC (Relato da Entrevistada A1).

Por fim, é importante notar que 14 dos entrevistados disseram ter realizado um trabalho sobre o tema RSC na faculdade. Todos avaliaram essa experiência como interessante. Isso sugere que há, sim, um interesse efetivo pelo tema. O que talvez não haja é uma resposta adequada das instituições a esse interesse.

Dessa forma, os resultados apontam que, mesmo a literatura destacando a necessidade do ensino da RSC em administração (Souza et al., 2003; Canopf e Passador, 2004; Muijen; 2004; Urdan e Huertas, 2004; Fourneau e Serpa, 2006; Gonçalves-Dias et al., 2006; Xavier et al., 2006; Medeiros et al., 2007), aos olhos desses alunos, o espaço dedicado ao tema não é suficiente, em termos quantitativos e qualitativos.

\subsubsection{Visão de RSC}

Coerentemente com o que se viu nos itens anteriores, a maioria dos entrevistados demonstrou ter uma visão ainda bastante limitada do conceito de RSC. Somente algumas dimensões foram mencionadas.

Alguns entrevistados descreveram a RSC como algo somente relacionado à dimensão social, dizendo que a RSC está ligada à sociedade, à comunidade (Wood, 1991a; Enderle e Tavis, 1998; Ashley, 2002).

Acho que RSC significa você ter responsabilidade com a comunidade e com a sociedade. Entender qual é o impacto que você causa neles e tentar mitigar esses impactos (Relato da Entrevistada A1). 
RSC é você tentar produzir para a sociedade algo além dos bens que você produz, quer dizer, dar um retorno à sociedade (Relato do Entrevistado E2).

Outros definiram a RSC levando em conta somente alguns stakeholders, seja meio ambiente e comunidade, seja comunidade e funcionários, mostrando que conhecem algumas dimensões da RSC (Wood, 1991a; Enderle e Tavis, 1998; Melo Neto e Froes, 1999; Ashley, 2002).

Na minha opinião, significa, no meu entendimento significa, é, uma consciência, uma responsabilidade que as pessoas, as empresas têm perante a sociedade, é, de ajudar o próximo, ajudar com todos os recursos que hoje não são possíveis em algumas áreas, como educação, saúde, é, ensino em geral, alimentação e meio ambiente também (Relato do Entrevistado E1).

Eu acho que RSC está voltado para as causas assim de meio ambiente, a sociedade, o que a empresa se preocupa com esses temas (Relato do Entrevistado E4).

Alguns entrevistados levaram em conta somente a dimensão ambiental (Enderle e Tavis, 1998; Ashley, 2002).

Você fazer, mas se preocupar também em não destruir. Fazer uma coisa, mas não fazer negócio que vá destruir. Mesmo que você destrua, que você depois tenha um programa pra que a coisa volte, tipo no caso que eu falei, reflorestamento, alguma coisa assim (Relato do Entrevistado C6).

Dois entrevistados expressaram uma visão assistencialista, levando em conta somente a filantropia (Carrol, 1991; Quazi e O’Brien, 2000). "RSC, pra mim, é ajuda das pessoas, das empresas, é, por parte responsável em doação, ou ajudas a comunidades a qual, por exemplo, uma empresa está atuando, é, naquele lugar para ajudar as pessoas que estão na volta dela. Acho que é mais ou menos isso" (Relato do Entrevistado C3). "RSC, para mim é a parte de colaborar para ajudar as ONGs, ajudar o próximo mais necessitado" (Relato da Entrevistada D5).

Poucos entrevistados mostraram ter uma visão mais ampla do que é RSC, dizendo que envolve diversos stakeholders (Wood, 1991a; Enderle e Tavis, 1998; Quazi e O'Brien, 2000; Ashley, 2002). Vale ressaltar que um entrevistado que definiu RSC de forma mais ampla realizou sua monografia sobre o tema.

É agir pensando em todos os envolvidos dentro de um determinado processo. Quando a gente pensa numa ação empresarial exclusivamente, a gente tem a comunidade, a sociedade, os trabalhadores, o cliente, o acionista. Quem mais 
eu posso falar? Tem aí uns 6 ou 7, sem citar autores, nada, temos uns 6 envolvidos dentro de um determinado processo. RSC é você agir de uma forma que não atrapalhe ou não diminua nenhum desses 6 envolvidos [...] eu lembrei [...] tem o meio ambiente (Relato do Entrevistado A3).

RSC significa criar valor para todos os stakeholders, as pessoas que são internamente, que trabalham internamente para a empresa e externamente, desenvolver uma sociedade também (Relato da Entrevistada C2).

Isso sugere que há realmente carência de informações sobre o tema. Por outro lado, chama atenção nos depoimentos a preocupação com o meio ambiente e com desigualdades sociais. Aos olhos dos entrevistados, a RSC está associada ao esforço de reduzir esses problemas, para os quais parecem ser bastante sensibilizados. Talvez, por isso, uma proporção tão significativa de entrevistados tenha se empenhado em realizar, ao longo da graduação, trabalhos sobre o tema.

\subsubsection{Dúvidas e questionamentos sobre RSC}

Muitos entrevistados possuem questionamentos e dúvidas sobre o tema RSC, principalmente dúvidas básicas, como o significado do conceito. "Vários. O próprio conceito do tema em si eu não domino" (Relato do Entrevistado A5). "É, talvez alguns. O que eu te falei, eu não sei se eu saberia definir exatamente o que seria RSC, entendeu? Seria uma, por exemplo" (Relato da Entrevistada D6).

Vários expressaram questionamentos sobre a prática da RSC. Trata-se de um ponto interessante e muito relevante. Em primeiro lugar porque este é um aspecto abordado pela literatura, principalmente no que diz respeito à implementação, avaliação, controle de projetos de RSC (Ashley, 2002; Snider et al., 2003; Barnett, 2007), mas sobre o qual ainda há lacunas (Mattingly e Berman, 2006). Se há um razoável consenso sobre a necessidade de adotar a RSC, o modo de fazê-lo ainda é objeto de vários debates, entre os quais o já citado na revisão de literatura sobre a relação estratégias empresariais versus RSC. Em segundo lugar, talvez isso explique, ao menos em parte, a insatisfação dos entrevistados em relação às abordagens dadas ao tema em sua formação. Mais do que sensibilização para o tema (que os entrevistados demonstram ter), o que eles parecem demandar são ferramentas conceituais e técnicas para colocar a RSC em prática e tomar decisões em suas atividades profissionais atuais e futuras. 
Como é que funciona o mecanismo, como seria trabalhar num departamento desses numa empresa, como seria coordenar um projeto desse (Relato da Entrevistada B3).

Não sei, como a gente colocaria a RSC dentro de uma empresa, maneiras de implementação e tudo (Relato do Entrevistado E3).

É, assim, é sempre difícil, assim, como estudei um pouco de treinamento e acho que tem o mesmo problema em RSC, que é mensurar o quanto que isso afeta. Talvez muita gente vê a parte de finanças, talvez fique vendo só os lucros e não saiba mensurar o quanto isso traz de retorno pra empresa. Então, vai ser muito difícil fazer esse tipo de análise, mas era interessante ver o quanto que isso retorna à empresa. Porque não tem jeito, acionista quer saber quanto que ele está ganhando, quanto que está entrando no bolso quando ele faz um investimento. Se você faz um investimento de RSC era bom saber o quanto isso te retorna (Relato do Entrevistado B6).

Claro que eu queria poder me aprofundar mais nisso, na questão que eu falei de, dos benefícios que você ganha, entendeu? Porque as empresas também não fazem isso só porque é bonito. Eles fazem também por causa disso. Saber um pouco mais disso, e acho que é isso (Relato do Entrevistado C6).

Outro aluno relatou ter dúvidas sobre mensurar o retorno da RSC para o país, mostrando que há aqueles que se preocupam com a questão do papel social das empresas.

[...] seria como a RSC mesmo dentro desse escopo mais restrito de ter uma orientação que seja estratégica pra empresa como ela pode contribuir com a sociedade e Estado na construção, na redução da pobreza e no desenvolvimento efetivo, de verdade, com números do país. Porque a RSC ainda pelas empresas é algo que não é muito mensurável: A gente ajuda 12 mil crianças. Eu acho isso lindo, mas eu quero assim, ver mais a médio e longo prazo como essas 12 mil crianças saíram daquela condição de pobreza e vieram a se tornar pessoas que vieram a compor uma população economicamente ativa no país (Relato do Entrevistado A3).

Dessa forma, a literatura que fala do ensino de RSC em administração (Souza et al., 2003; Canopf e Passador, 2004; Muijen; 2004; Urdan e Huertas, 2004; Fourneau e Serpa, 2006; Gonçalves-Dias et al., 2006; Xavier et al., 2006; Medeiros et al., 2007) parece estar em concordância com as demandas dos alunos. Chama atenção também a visão realista de determinados estudantes, que indagam sobre os benefícios concretos da RSC para as organizações 
e para a sociedade. Ou seja, observou-se que há dúvidas e questionamentos sobre como a RSC deve ser posta em prática no dia a dia da organização e sobre como seus benefícios para as empresas e para a sociedade podem e devem ser avaliados.

\subsubsection{Aplicação da RSC na prática de suas atividades profissionais}

Alguns entrevistados disseram que as empresas em que trabalharam/trabalham não praticam a RSC, outros responderam que praticam. Dos que responderam que praticam, alguns já participaram de atividades desenvolvidas pela empresa, inclusive voluntariado. Essas experiências foram, na maioria das vezes, ligadas à dimensão social da RSC (Wood, 1991a; Enderle e Tavis, 1998; Ashley, 2002) e algumas ligadas à dimensão ambiental (Enderle e Tavis, 1998; Ashley, 2002). Foi observado que aqueles que tiveram experiência na área se mostraram mais seguros em relação ao assunto e conhecedores do conceito de RSC. Alguns expressam opiniões sobre o trabalho realizado pelas empresas:

Tenta pôr, mas acho que tem muita coisa a desenvolver ainda [...] tentando oferecer treinamento para os funcionários, dando bolsas para os funcionários em instituições de ensino, criando uma responsabilidade das pessoas imprimir menos, gastar menos água (Relato da Entrevistada C2).

Ah, tem vários. Ela faz programas com alunos universitários. É uma empresa bem socialmente responsável, bem consciente mesmo. Tem programas de capacitação, tem muita coisa (Relato da Entrevistada B3).

De modo geral, os entrevistados demonstraram ter um bom nível de conhecimento sobre os programas de RSC desenvolvidos pelas empresas nas quais trabalhavam ou haviam trabalhado. Isto provavelmente se deve ao trabalho de comunicação realizado internamente pelas próprias empresas. Ainda assim, a segurança com que os entrevistados responderam às questões relacionadas a esse assunto demonstra, novamente, seu interesse pelo tema.

\subsubsection{Visão sobre RSC em relação à faculdade em que estudou}

Muitos entrevistados consideram que sua faculdade não é capaz de formar gestores socialmente responsáveis, já que o tema não é muito falado e discutido. E, para eles, as faculdades devem mudar, passando a realizar maiores esforços para formar gestores socialmente responsáveis. 
Uma das ações que a maioria dos entrevistados considerou ser fundamental para que a faculdade passe a formar gestores socialmente responsáveis é a inclusão de uma disciplina relacionada ao tema e a mudança em ementas de disciplinas como marketing e recursos humanos, para que passem a abordar o tema e relacionem à prática da administração. Assim, na visão dos entrevistados, poderiam ser superadas suas dúvidas em relação ao conceito de RSC, conforme relatado por eles.

Incorporar esse tema a todas as disciplinas, não só, também ter uma disciplina voltada exclusivamente pra isso, mas não ficar só no teórico, como a gente coloca em prática, mudar o pensamento voltado pra isso. Mas não só uma matéria exclusiva, mas também tentar incorporar isso às outras, esse tema (Relato da Entrevistada B4).

Outros entrevistados sugeriram que seria interessante se as faculdades, além de ter aulas e trabalhos sobre o assunto, promovessem eventos, como workshops, seminários e exposições sobre o tema, para criar um ambiente propício para a discussão sobre o assunto com o meio empresarial e para ter contato com casos práticos.

[...] podendo ter a chance de fazer um evento, um evento, uma semana de administração com uma palestra pra RSC, pra poder estar convidando a comunidade empresarial do município para poder estar chamando os outros alunos pra assistir [...] eu acho que palestra e trazer a classe empresarial pra falar sobre o tema, debater, é muito importante [...] (Relato do Entrevistado A6).

Hum, maior, acho que não basta só também, só na teoria também. Acho que evidências práticas, assim, workshops sobre isso, é, iniciativas externas, como movimentos [...] (Relato do Entrevistado E5).

Vários entrevistados sugeriram que as universidades devem ensinar a prática da RSC, através de trabalhos, por exemplo. Isso mostra que os alunos demandam esse tipo de ensino e então sugere que essa metodologia poderia ser adotada.

[...] acho que poderia ter também dentro dessas cadeiras, questões tipo, ah, visita a empresa, avalia a responsabilidade social da empresa, o que empresa vai fazendo, propõe alguma coisa pra essa empresa. Tem uma série de trabalhos assim que com certeza os alunos iam fazer, iam gostar bastante. Só que a gente não tem aqui. Pelo menos eu não tive, agora eu estou saindo da faculdade (Relato do Entrevistado C4). 
[...] principalmente, incentiva a visita a empresas socialmente responsáveis, identificação de projetos e fazer esse tipo de análise mesmo, um impacto, análise de impacto de uma organização no meio. Seria interessante pra fazer numa faculdade de negócios, como é a minha (Relato do Entrevistado D4).

Projeto em prática, principalmente nas segundas avaliações, pra realmente ser um prerequisito para aprovar aluno [...] (Relato do Entrevistado E2).

De modo geral, os depoimentos colhidos sugerem que os estudantes não se satisfazem com uma abordagem meramente teórica. Em sua visão, tal abordagem parece estar associada à necessidade de se preocupar com o tema e, nesse sentido, soma pouco a seus conhecimentos. Como foi visto, os estudantes pesquisados demonstram estar sensibilizados para o tema RSC. O que eles desejam saber é como colocar a RSC na prática das organizações e, nesse ponto, o ensino oferecido nas universidades parece trazer contribuições bastante limitadas em face de suas expectativas. Outro ponto que chama atenção é o interesse em ter contato com a visão das empresas, saber o que efetivamente se faz em termos de RSC, ouvir empresários e executivos que lidam com decisões, programas, ações de RSC.

\section{Considerações finais e sugestões para futuras pesquisas}

Esse estudo investigou a visão de estudantes formandos em administração sobre a RSC e seu ensino em cursos de graduação. Os resultados apontam que os informantes têm interesse no tema e se preocupam com as questões relacionadas à RSC. Porém, não priorizam em sua formação as disciplinas eletivas oferecidas pelas instituições de ensino.

Paradoxalmente, julgam que o espaço dedicado ao tema é insuficiente. É possível que isso se deva ao modo como é tratado em disciplinas obrigatórias, como marketing e recursos humanos. Em sua visão, a abordagem, nesse contexto, é superficial e, muitas vezes, desestruturada. Esse julgamento talvez se deva à forte exposição ao tema RSC que ocorre fora das salas de aula. Isso faz com que os alunos estejam sensibilizados para essas questões, tornando redundantes os esforços esparsos de alguns professores em inserir discussões sobre a importância da RSC nas salas de aula. Na realidade, como mostram os depoimentos colhidos, os alunos já estão cientes da importância da RSC, especialmente no contexto brasileiro. Eles também demonstram isso ao eleger esse tema para a realização de trabalhos e monografias. O que falta, a seus olhos, 
são insumos sobre como colocar a RSC em prática. Nesse sentido, apesar de sua insegurança quanto ao conceito de RSC, eles levantam dúvidas e questões pertinentes, que são debatidas pela literatura. Porém, desconhecem esses debates, bem como as proposições mais atuais sobre a implementação da RSC e as discussões a respeito da questão da legitimidade da RSC nas empresas, conforme Faria e Sauerbronn (2005).

Os resultados da pesquisa sugerem algumas medidas práticas para as instituições de ensino que desejam, atendendo à recomendação das diretrizes curriculares nacionais para o curso de administração (Souza et al., 2003; Canopf e Passador, 2004), reforçar a presença do tema RSC na formação que oferecem aos estudantes de administração. São elas:

- Formalização da inclusão do tema RSC em ementas de disciplinas e currículo, com a possibilidade de inclusão de disciplinas obrigatórias sobre o tema ou a inclusão dessa temática nas disciplinas relacionadas. Tal medida favoreceria o tratamento mais sistemático e completo do tema, atendendo à demanda dos alunos e reduzindo o descompasso percebido por eles entre o tratamento dado ao assunto na mídia e nas empresas onde estagiam ou trabalham em relação ao que a universidade oferece.

v Mudança de foco no tratamento dado à RSC na universidade: mais que sensibilizar os alunos para esse tema (eles demonstram estar conscientes de sua importância), é preciso focar a implementação do conceito nas organizações, apresentar instrumentos de análise para a tomada de decisões, ferramentas para a construção e avaliação de programas de RSC, oferecer uma formação capaz de preparar os estudantes para decidir, planejar e executar programas e ações de RSC.

- Abordagem prática: promover a exposição a iniciativas reais de RSC por meio de estudos de caso, visita a empresas, palestras de executivos e outros. Novamente, não é preciso conscientizar e sim mostrar como a RSC pode ser colocada em prática.

Como sugestão para futuras pesquisas, tais medidas poderiam ser submetidas à avaliação de uma amostra representativa de alunos de graduação em administração, bem como a membros do corpo acadêmico das faculdades estudadas (professores, coordenadores) e executivos que atuam no ambiente empresarial. 


\section{Referências}

AAKER, D.A. et al. Pesquisa de marketing. São Paulo: Atlas, 2004.

ASHLEY, P. A. Ética e responsabilidade social nos negócios. São Paulo: Saraiva, 2002.

AGUILERA, R.V. et al. Putting the S Back in corporate social responsibility: a multilevel theory of social change in organizations. Academy of Management Review, v. 32, n. 3, p. 836-863, 2007.

ATAKAN, M.G.S.; EKER, T. Corporate identity of a socially responsible university - a case from the Turkish higher education sector. Journal of Business Ethics, v. 76, p. 55-68, 2007.

AUGER, P. et al. What will consumers pay for social product features? Journal of Business Ethics, v. 42, n. 3, p. 281-304, 2003.

BARNETT, M.L. Stakeholder influence capacity and the variability of financial returns to corporate social responsibility. Academy of Management Review, v. 32, n. 3, p. 794-816, 2007.

BONATTO, A. et al. Ética e responsabilidade social: um estudo comparativo do balanço social da empresa Eletrocar. In: ENANPAD, 31. Anais... Rio de Janeiro: Anpad, 2007.

BOWEN, F. Corporate social strategy: competing views from two theories of the firm. Journal of Business Ethics, v. 75, p. 97-113, 2007.

CANOPF, L.; PASSADOR, C.S. A responsabilidade social na graduação em administração da região sudoeste do Paraná: obrigação cumprida ou demanda atendida? In: ENANPAD, 28. Anais... Curitiba: Anpad, 2004.

CARROLL, A.B. The pyramid of corporate social responsibility: toward the moral management of organizational stakeholders. Business Horizons, p. 39-48, July/Aug. 1991.

CARSON, T.L. Self-interest and business ethics: some lessons of the recent corporate scandals. Journal of Business Ethics, v. 43, p. 389-394, 2003.

COLLIER, J.; WANDERLEY, L. Thinking for the future: global corporate responsibility in the twenty-first century. Futures, p. 1-14, 2004.

DETIENNE, K.B.; LEWIS, L.W. The pragmatic and ethical barriers to corporate social responsibility disclosure: the Nike case. Journal of Business Ethics, v. 60, p. 359-376, 2005. 
DUFLOTH, S.C.; BELLUMAT, C.C. A disseminação de informações das ações de responsabilidade social das empresas. In: ENANPAD, 29. Anais... Brasília: Anpad, 2005.

ENDERLE, G.; TAVIS, L.A. A balanced concept of the firm and the measurement of its long-term planning and performance. Journal of Business Ethics, v. 17, n. 11, p. 1129-1144, 1998.

FARIA, A.; SAUERBRONN, F.F. Em defesa de uma abordagem menos "estratégica" para a responsabilidade social. In: ENCONTRO DE ESTUDOS EM ESTRATÉGIA, 2. Anais... Rio de Janeiro: Anpad, 2005.

FARIA, A.; SAUERBRONN, F.F. A responsabilidade social é uma questão de estratégia? Uma abordagem crítica. Revista de Administração Pública, Rio de Janeiro, v. 42, n. 1, p. 7-33, jan./ fev. 2008.

FOURNEAU, L.F.; SERPA, D.A.F. Percepções e opiniões sobre o ensino da ética em administração: a voz dos alunos. In: ENANPAD, 30. Anais... Salvador: Anpad, 2006.

GEPHART, R.P. Qualitative research and the Academy of Management Journal. Academy of Management Journal, v. 47, n. 4, p. 454-462, 2004.

GERDE, V.W. The design dimensions of the just organization: an empirical test of the relation between organization design and corporate social performance. Business \& Society, v. 40, n. 4, p. 472-477, 2001.

GIL, A.C. Como elaborar projetos de pesquisa. São Paulo: Atlas, 1987.

GONÇALVES-DIAS, S.L.F. et al. A inserção da temática ambiental em cursos de administração: uma tipologia para (re)pensar a formação de administradores. In: ENANPAD, 30. Anais... Salvador: Anpad, 2006.

HANSON, D.; GRIMMER, M. The mix of qualitative and quantitative research in major marketing journals, 1993-2002. European Journal of Marketing, v. 41, n. 1/2, p. 58-70, 2007.

HIGUCHI, A.K.; VIEIRA, F.G.D. Responsabilidade social corporativa e marketing social corporativo: uma proposta de fronteira entre estes dois conceitos. In: ENANPAD, 31. Anais... Rio de Janeiro: Anpad, 2007.

HOND, F.D.; BAKKER, F.G. A. Ideologically motivated activism: how activist groups influence corporate social change activities. Academy of Management Review, v. 32, n. 3, p. 901-924, 2007.

KATES, S. A qualitative exploration into voters' ethical perceptions of political advertising: discourse, disinformation, and moral boundaries. Journal of Business Ethics, v. 17, p. 1871-1885, 1998. 
KLEIN, J.G. Corporate social responsibility: a consumer perspective. Advances in Consumer Research, v. 31, p. 101-103, 2004.

MARQUIS, C. et al. Community isomorphism and corporate social action. Academy of Management Review, v. 32, n. 3, p. 925-945, 2007.

MATTEN, D.; MOON, J. "Implicit" and "explicit" CSR: a conceptual framework for a comparative understanding of corporate social responsibility. Academy of Management Review, v. 33, n. 2, p. 404-424, 2008.

MATTINGLY, J.E.; BERMAN, S.L. Measurement of corporate social action: discovering taxonomy in the Kinder Lydenburg Domini Rattings Data. Business \& Society, v. 45, n. 1, p. 20-46, 2006.

MEDEIROS, C.R.O. et al. A formação do administrador e a responsabilidade corporativa: ambiguidades e contradições no comportamento do futuro gestor. In: ENANPAD, 31. Anais... Rio de Janeiro: Anpad, 2007.

MELO NETO, F.P.; FROES, C. Responsabilidade social \& cidadania empresarial: a administração do terceiro setor. Rio de Janeiro: Qualitymark, 1999.

MOHR, L.A.; WEBB, D.J. The effects of corporate social responsibility and price on consumer responses. The Journal of Consumer Affairs, v. 39, n. 1, p. 121-147, 2005 .

MUIJEN, H.S.C.A. Corporate social responsibility starts at university. Journal of Business Ethics, v. 53, p. 235-246, 2004.

NEUBAUM, D.O.; ZAHRA, S.A. Institutional ownership and corporate social performance: the moderating effects of investment horizon, activism and coordination. Journal of Management, v. 32, n. 1, p. 108-131, 2006.

PEREIRA, W.A.; CAMPOS FILHO, L.A.N. Investigação sobre as semelhanças entre os modelos conceituais da responsabilidade social corporativa. In: ENANPAD, 30. Anais... Salvador: Anpad, 2006.

QUAZI, A.M.; O'BRIEN, D. An empirical test of a cross-national model of corporate social responsibility. Journal of Business Ethics, v. 25, p. 33-51, 2000.

RODRÍGUEZ, L.C.; LEMASTER, J. Voluntary corporate social responsibility disclosure: SEC "CSR Seal of Approval". Business \& Society, v. 46, n. 3, p. 370-385, 2007.

SANTOS., G.J. Cidadania corporativa ou ferramenta de legitimação? Uma análise da institucionalização das práticas de responsabilidade social. In: ENANPAD, 32. Anais... Rio de Janeiro: Anpad, 2008. 
SCHOMMER, P.C.; ROCHA, F.C.C. As três ondas da gestão socialmente responsável no Brasil: dilemas, oportunidades e limites. In: ENANPAD, 31. Anais... Rio de Janeiro: Anpad, 2007.

SEN, S.; BHATTACHARYA, C.B. Does doing good always lead to doing better? Consumer reactions to corporate social responsibility. Journal of Marketing Research, v. 38, n. 2, p. 225-243, 2001.

SHAH, S.K.; CORLEY, K.G. Building better theory by bridging the quantitative-qualitative divide. Journal of Management Studies, v. 43, n. 8, p. 1821-1835, 2006.

SNIDER, J.; HILL, R.P.; MARTIN, D. Corporate social responsibility in the $21^{\text {st }}$ century: a view from the world's most successful firms. Journal of Business Ethics, v. 48, p. 175-187, 2003.

SOUZA, W.J. et al. Mercado, ética e responsabilidade social na formação dos profissionais de administração e de ciências contábeis: uma análise teórico-comparativa sob a ótica das diretrizes curriculares nacionais. In: ENANPAD, 27. Anais... Atibaia: Anpad, 2003.

URDAN, A.T.; HUERTAS, M.K.Z. A ética no ensino de marketing: graduandos em administração no Brasil versus Estados Unidos. In: ENANPAD, 28. Anais... Curitiba: Anpad, 2004.

WOOD, D.J. Corporate social performance revisited. Academy of Management Review, v. 16, n. 4, p. 691-718, 1991a.

WOOD, D.J. Toward improving corporate social performance. Business Horizons, p. 66-73, July/Aug. 1991b.

XAVIER, A.M. et al. Formação profissional e ética no curso de administração: leituras de estudantes de graduação de uma faculdade particular. In: ENANPAD, 30. Anais... Salvador: Anpad, 2006. 